\title{
Toward the integration of expert knowledge and instrumental data to control food processes: Application to Camembert-type cheese ripening
}

\author{
M. Sicard, N. Perrot, ${ }^{1}$ M.-N. Leclercq-Perlat, C. Baudrit, and G. Corrieu \\ Unité Mixte de Recherche Génie et Microbiologie des Procédés Alimentaires (UMR GMPA), Institut National de la Recherche Agronomique, \\ 78850 Thiverval-Grignon, France
}

\begin{abstract}
Modeling the cheese ripening process remains a challenge because of its complexity. We still lack the knowledge necessary to understand the interactions that take place at different levels of scale during the process. However, information may be gathered from expert knowledge. Combining this expertise with knowledge extracted from experimental databases may allow a better understanding of the entire ripening process. The aim of this study was to elicit expert knowledge and to check its validity to assess the evolution of organoleptic quality during a dynamic food process: Camembert cheese ripening. Experiments on a pilot scale were carried out at different temperatures and relative humidities to obtain contrasting ripening kinetics. During these experiments, macroscopic evolution was evaluated from an expert's point of view and instrumental measurements were carried out to simultaneously monitor microbiological, physicochemical, and biochemical kinetics. A correlation of $76 \%$ was established between the microbiological, physicochemical, and biochemical data and the sensory phases measured according to expert knowledge, highlighting the validity of the experts' measurements. In the future, it is hoped that this expert knowledge may be integrated into food process models to build better decision-aid systems that will make it possible to preserve organoleptic qualities by linking them to other phenomena at the microscopic level.
\end{abstract}

Key words: cheese ripening, expert knowledge, process control, knowledge integration

\section{INTRODUCTION}

Camembert cheese ripening is a complex system with numerous interacting variables that are responsible for physical, chemical, biological, and structural changes. Cheese quality depends on environmental factors (relative humidity, temperature, gas concentration in the

Received December 9, 2009

Accepted July 1, 2010.

${ }^{1}$ Corresponding author: nperrot@grignon.inra.fr chamber) and on the interactions between inoculated microorganisms and curd substrates that result from variations in raw milk quality and cheesemaking conditions.

Numerous studies have been carried out to attempt to understand this process from a microbial, physicochemical, biochemical, and sensory point of view. Authors such as Leclercq-Perlat et al. (2004) have studied microflora interactions to evaluate their synergistic effects on substrate consumption. Instrumental methods have also been developed to provide an objective method of bio- and physicochemical cheese characterization during the Camembert cheese ripening process (Martin-del Campo et al., 2007; Peres et al., 2002). More recently, some authors have attempted to model part of the process. Helias et al. (2007) established a dynamic model of Camembert mass loss resulting from physical and biological phenomena during the ripening process. However, microflora growth prediction was not integrated into the model and knowledge is still lacking. Large databases are required to understand the numerous variables and their interactions. These databases are generally nonexistent because of time limits, financial constraints, and scientific and technological obstacles. As a result, modeling such complex systems remains a challenge.

Among the food end-product qualities to be controlled, sensory quality is essential because it determines the choice and preferences of consumers. Managing sensory properties at the manufacturing stage with the aim of controlling them is particularly difficult. Few sensors are available to carry out such complex measurements (Trystram, 1996). Knowledge about the links between microbiological, physicochemical, and biochemical phenomena and the evolution of cheese sensory properties is still lacking.

Operators often play an important role and, in practice, interact with automatic systems to assess the sensory properties of the product on-line and to adjust the process (Perrot et al., 2004). Operator assessment and reasoning still play a major role in the cheese ripening process (Lemoine, 2001), especially concerning sensory property control. In factories, the cheesemaker usually 
controls the ripening process through a limited number of instrumental measurements and empirical sensory perceptions (Perrot, 2004; Picque et al., 2006). For example, Perrot (2004) successfully built a decisionsupport system based on expert skills to control the ripening of a soft mold cheese. The effect of the results was limited because microbial kinetics were not integrated into the system.

Within this context, our global aim is to propose new conceptual frameworks to help integrate and unify different types of fragmented knowledge for the prediction of food model kinetics at different scales, ranging from the macroscopic sensory scale to the microscopic scale. The combination of the disseminated knowledge could then lead to a better understanding of the entire network of interactions that take place between different levels of food processes such as cheese ripening.

This work is an initial step toward reaching this goal. It aims at demonstrating the coherence of the cheesemaker's knowledge in relation to the other scales for further knowledge integration. The validity of the knowledge is checked by comparing it to microbiological, physicochemical, and biochemical evolutions. A way of linking both scales is proposed.

\section{MATERIALS AND METHODS}

\section{Eliciting and Formalizing Expert Knowledge}

Through years of practice, some cheesemakers become experts at controlling the process. Our aim was to elicit their knowledge to better understand the ripening process in terms of its dynamics.

The first part of the method was to identify experts of the Camembert ripening process. Although numerous studies in psychology and in artificial intelligence analyze expertise, it is not possible to provide a definition of this notion that is both operational and universally accepted (Shanteau, 1992). In this study, experts were chosen based on their consistent practice, high level of performance, and peer recognition. The criteria used were those recommended by Cellier et al. (1997), Hoffman et al. (1995), and, more recently, FarringtonDarby and Wilson (2006).

Four experts were interviewed. Each had more than $15 \mathrm{yr}$ of practice in cheese ripening and recognized expertise concerning the ripening of soft mold cheeses. One was an expert from a cheese factory and 2 were cheese process consultants for the dairy industry. The last was a cheesemaker from our laboratory who had worked in the area of Camembert manufacturing and ripening processes for more than $15 \mathrm{yr}$. The 4 experts had a high level of skill in Camembert production. Each of them was interviewed during 1 or 2 sessions (3-6 h).
Each of the elicitation sessions was attended by 1 expert and 2 interviewers. Two hours was allotted for each interview. A set of predetermined structured questions was used to direct the interviews. Experts were not pressured into following any particular order of questioning. Instead, questions were used to orient the direction of the expert's thinking. The aim was to extract knowledge in an unbiased form as far as possible. During each session, notes were taken and audio tapes were made. After the session, the tapes were replayed several times to make sure the notes were accurate and complete.

In cheese ripening, as in every complex food process, most of the control measures are performed based on the experts' sensory perceptions (Perrot, 2004; Picque et al., 2006). Interviews were therefore conducted to identify the sensory information used by the expert to control the ripening process. The aim was also to elicit the standard changes in the sensory indicators during the ripening step. The method developed by Curt et al. (2004) was used. Therefore, during the interview with the expert, the aim was to collect the information necessary to develop "sensory indicators": the indicator used, its definition, operating conditions, answer scale, and references such as scale anchorage points.

Curt et al. (2004) developed a method adapted from the classical sensory method, adjusted to the constraints of an on-line sensory evaluation. The experts' skills are therefore transmitted to operators who become "measuring instruments" capable of evaluating product sensory changes throughout the process. A comparison of the 2 methods is proposed in Table 1. The main characteristic of on-line sensory evaluation is that the assessment scales are discontinuous and anchored by ordinate symbolic data.

\section{Cheese Ripening Trials}

A large number of microbiological, biochemical, and physicochemical parameters influence soft mold cheese ripening. Quality depends on the raw material, curd production, and ripening conditions (Lenoir, 1983). In this study, experiments were carried out at different temperatures and relative humidities $(\mathbf{R H})$ to ripen Camembert-type cheese. The effect of the 2 factors was evaluated on several ripening kinetics: microbial evolution, biochemical, physicochemical, and organoleptic property evolution. With regard to the nonquadratic variations of the considered variables in relation to the temperature and relative humidity of the ripening chamber, experimental plans were not adapted to our purpose. The sets of ripening conditions were then chosen to cover the widest range of variations possible for the state variables space. 


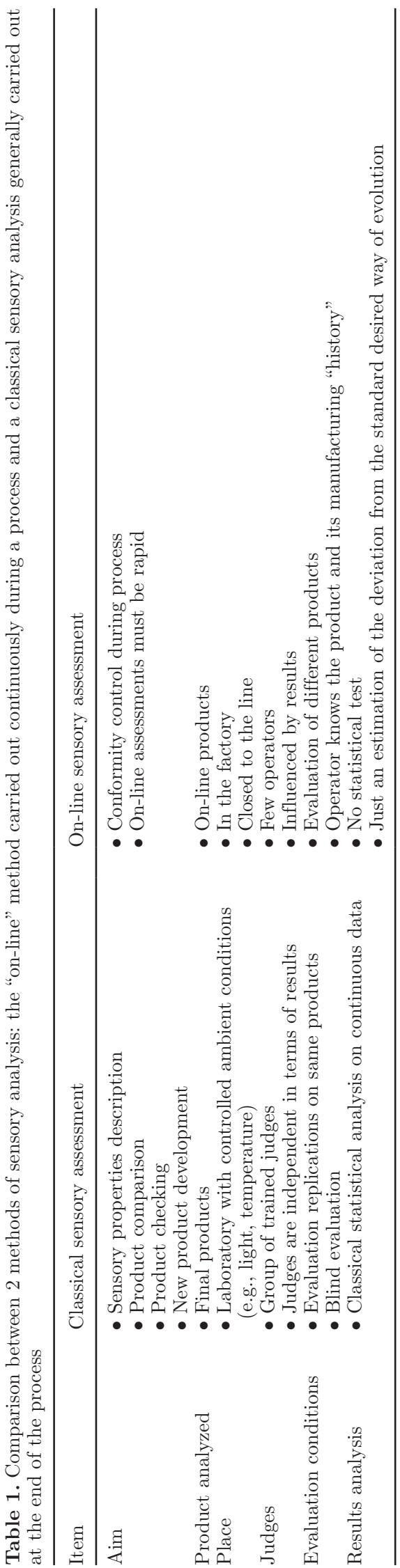

Table 2. Key experiments (a1, a2, b1, b2, c11, and c12 represent different trials) conducted at the pilot plant

\begin{tabular}{lccc}
\hline & \multicolumn{3}{c}{ Temperature $\left({ }^{\circ} \mathrm{C}\right)$} \\
\cline { 2 - 4 } $\begin{array}{l}\text { Relative } \\
\text { humidity }(\%)\end{array}$ & 8 & 12 & 16 \\
\hline 98 & $\mathrm{~b} 1$ & c11 and $\mathrm{c} 12$ & $\mathrm{a} 1$ \\
92 & $\mathrm{~b} 2$ & & $\mathrm{a} 2$ \\
88 & & \\
\hline
\end{tabular}

The results are presented in this work for 6 key trials (a1, a2, b1, b2, c11, and c12; Table 2). Reproducibility of the experiments was evaluated through the 2 similar experiments, $\mathrm{c} 11$ and $\mathrm{c} 12$.

\section{Cheese Manufacturing and Ripening}

Camembert-type soft mold cheeses were produced as detailed in Leclercq-Perlat et al. (2004) on a pilot scale under aseptic conditions in a sterilized $2-\mathrm{m}^{3}$ cheesemaking chamber in which coagulation, cutting, draining, and shaping of the curds were performed. The chamber temperature was maintained at $28 \pm 1^{\circ} \mathrm{C}$, and all of the nonautoclavable equipment was cleaned and sterilized as described previously (Leclercq-Perlat et al., 2004).

For each cheesemaking trial, $200 \mathrm{~L}$ of milk was used to make 100 cheeses. The raw milk was obtained from the experimental farm of the AgroParisTech Institute (Thiverval-Grignon, France). Milk was standardized at $2.9 \mathrm{~g}$ of fat/100 $\mathrm{g}$ by mixing skim and full-cream milk, and at $3.5 \mathrm{~g}$ of total protein $/ 100 \mathrm{~g}$ by adding milk powder (582, Ingredia, Haras, France). After mixing, the milk was pasteurized for $2 \mathrm{~min} 30 \mathrm{~s}$ at $77 \pm 1^{\circ} \mathrm{C}$ and cooled to $34 \pm 1^{\circ} \mathrm{C}$. This treatment is commonly used by the industry for manufacturing Camembert with pasteurized milk. The $\mathrm{pH}$ of the milk varied between 6.5 and 6.6 .

The milk was inoculated $(15 \mathrm{~mL} / \mathrm{L})$ with lactic acid bacteria (Flora Danica lyophilizate, CHN11, Chr. Hansen, Arpajon, France), Kluyveromyces marxianus (448, GMPA collection, GMPA, Thiverval Grignon, France), Geotrichum candidum (Degussa, D; Degussa Corp., La Ferte sous jouarre, France), Penicillium camemberti (Degussa, R), and Brevibacterium aurantiacum (ATCC9175; American Type Culture Collection, Manassas, VA) as ripening flora. When the tank was full, the concentrations of K. lactis, G. candidum, P. camemberti, and B. aurantiacum were $4 \times 10^{3} \mathrm{cfu} / \mathrm{mL}, 80$ $\mathrm{cfu} / \mathrm{mL}, 8.1 \times 10^{3} \mathrm{cfu} / \mathrm{mL}$, and $2.7 \times 10^{4}$ spores $/ \mathrm{mL}$, respectively. Because of lactic acid bacteria activity, the milk pH reached 6.3 after 80 to $110 \mathrm{~min}$. The coagulant (rennet containing $520 \mathrm{mg}$ of chymosin/L, Chr. Hansen) was then added $(20 \mathrm{~mL} / 100 \mathrm{~L})$. The coagulation time was approximately $20 \mathrm{~min}$ and the curd was cut 
Table 3. Precision of the measurements for the observed variables during cheese ripening

\begin{tabular}{lc}
\hline Measurement & Precision \\
\hline $\mathrm{pH}$ & 0.05 \\
Lactose $(\mathrm{g} / \mathrm{kg})$ & 0.6 \\
Lactate $(\mathrm{g} / \mathrm{kg})$ & 1.5 \\
Brevibacterium aurantiacum $\left(\log _{10} \mathrm{cfu} / \mathrm{g}\right)$ & 0.5 \\
Geotrichum candidum $\left(\log _{10} \mathrm{cfu} / \mathrm{g}\right)$ & 0.5 \\
Kluyveromyces marxianus $\left(\log _{10} \mathrm{cfu} / \mathrm{g}\right)$ & 0.5 \\
Penicillium camemberti $\left(\log _{10} \mathrm{spores} / \mathrm{g}\right)$ & 1 \\
\hline
\end{tabular}

into cubes after $40 \mathrm{~min}$ of firming. Approximately $80 \mathrm{~L}$ of whey was drained after $40 \mathrm{~min}$ to obtain an average cheese DM of between 40 and $42 \%$. It was then shaped in polyurethane molds (diameter: $110 \mathrm{~mm}$; height: 77 $\mathrm{mm}$ ) to produce cheeses weighing approximately 300 g. The molds were inverted twice after $30 \mathrm{~min}$ and 5 h. Three hours after molding, the temperature of the cheesemaking chamber was reduced to 20 to $22^{\circ} \mathrm{C}$, and $24 \mathrm{~h}$ after the molding, the cheeses were plunged into sterile brine $(330 \mathrm{~g}$ of $\mathrm{NaCl} / \mathrm{L}$, at $\mathrm{pH} 5.5)$ at $14 \pm 1^{\circ} \mathrm{C}$ for $25 \mathrm{~min}$. They were then transferred to the ripening chamber that had been previously sterilized with peracetic acid. The transfer time is defined as time zero of ripening. They were initially maintained at $12^{\circ} \mathrm{C}$ and $85 \% \mathrm{RH}$ for $24 \mathrm{~h}$, and then at a temperature and a $\mathrm{RH}$ determined by our experiments, with partial renewal of the gaseous atmosphere $\left(\mathrm{CO}_{2}\right.$ varied from 0 to $\left.0.4 \%\right)$. The cheeses were turned on $\mathrm{d} 5$. The temperature and $\mathrm{RH}$ were changed on $\mathrm{d} 15$. Cheeses were wrapped on $\mathrm{d}$ 14 and ripened at $4{ }^{\circ} \mathrm{C}$ until d 41 .

Differences in lactate concentrations on d 0 were due to the initial lactose concentrations and the activities of lactic acid bacteria. The initial lactose concentration varied from 48 to $52 \mathrm{~g}$ of lactose per liter, depending on the trial. A new lactic acid bacterium starter was prepared for each trial.

A combined sensor (Vaisala, HMP 243 Dewpoint transmitter, Etoile Internationale, Paris, France) measured the temperature and $\mathrm{RH}$ of the ripening chamber. Temperature and $\mathrm{RH}$ conditions were then automatically regulated over $15 \mathrm{~d}$ with acquisition every minute, by a software program developed in house (CRIC software, GMPA, Thiverval-Grignon, France). Concerning atmospheric conditions, the ripening trials were performed with a periodically renewed atmosphere to maintain the $\mathrm{CO}_{2}$ concentration under $0.4 \%$ and limit its effect on ripening (Picque et al., 2006). Carbon dioxide concentration was measured by an Iridium 100 infrared analyzer (City Technology, Portsmouth, UK) sensor.

Physicochemical, biochemical, and microbiological measurements were made off line. One cheese was removed daily for the first $15 \mathrm{~d}$ and then weekly after wrapping. , Determinations of DM, lactose, and lactate contents and $\mathrm{pH}$ were performed for each cheese. The kinetics of the main microorganisms, $K$. marxianus, $G$. candidum, and B. aurantiacum, were also monitored. It was difficult to evaluate the growth of $P$. camemberti because the sampling technique destroyed the mycelia (Molimard et al., 1995; Aldarf et al., 2002). All of these analyses were carried out as described previously in Leclercq-Perlat et al. (2004). The precision of the measurements is presented in Table 3 .

\section{Monitoring of Cheese Sensory Properties}

Our aim was to monitor cheese ripening trials as an expert would. Operators were trained to be considered as measuring instruments on the sensory indicators used by the experts and elicited during the interviews. The experts' sensory indicators were transmitted to a panel of 4 assessors who performed the sensory evaluation of the cheese during the ripening trials. The panel consisted of males and females between 25 and $50 \mathrm{yr}$ old. They were recruited according to their motivation and availability. The expert chosen as a reference to train the assessors had more than 15 yr of experience in soft mold cheeses. Six sessions were devoted to training, evaluation, and validation before the panel's performance was validated. For all the sessions, we used Camembert cheeses provided by a dairy company.

During the trials, evaluations took place next to the cheese ripening pilot plant in a temperature-controlled room, under neon lights, to have relatively constant evaluation conditions. The evaluations were carried out every day for the first $15 \mathrm{~d}$ of ripening. After wrapping, the cheeses were evaluated every week until $d$ 41 of ripening. Therefore, for each ripening trial, 19 samples of Camembert underwent analysis during the ripening process. The sensory kinetics of ripening were thus characterized.

\section{Data Analysis}

Microbiological, Physicochemical, and Biochemical Data Processing. To obtain a global view of the microbiological, physicochemical, and biochemical kinetics throughout ripening, a principal components analysis (PCA) was performed on the data. Principal components analysis is based on a linear projection of multidimensional data onto different coordinates based on maximum variance and minimum correlation (Saporta, 2006). Principal components analysis attempts to identify a minimum number of components to account for the majority of the variation in the original data. The first component extracted in a PCA accounts for a maximal amount of total variance in the observed 
variables. Typically, the second component is correlated with some of the observed variables that did not display strong correlations with the first component. The successive components, identified progressively, account for smaller portions of the total sample variance. The PCA was performed using the "princomp" function of the Matlab Statistics Toolbox (2007 version; Mathworks, Natick, MA).

Sensory Data Processing. Assessors' scores were collected and analyzed as instrumental data using Matlab software, as were all the data treated in this paper. The scales used for evaluations were discontinuous (symbolic data). These symbolic data were processed as described by Ioannou et al. (2002). The comparison of symbolic data was carried out by calculating a compatibility measurement (Bouchon-Meunier et al., 1996). Measurements $[\mathrm{M} i(j)]$ were considered compatible when their differences for the measurement $i$ were below 0.5 . This tolerance of 0.5 is accepted according to the expert (Ioannou et al., 2002). For example, if the expert assessed a cheese sample (measurement $i$ ) at a humidity level of 3 ("strongly wet"), the score given by an assessor (e.g., assessor 1: $j=1$ ) had to be between 2.5 and 3.5 to be compatible. In this case, $\mathrm{C} i(1)$ would then be set to 1 . In the case of a noncompatible measurement; that is, $<2.5$ or $>3.5, \mathrm{C} i(1)$ would be equal to 0 . The performance $P$ of the assessor $j$ is therefore the sum of the measurement $i$ with a compatible score on the total number of measurements $n$, as follows:

$$
P(j)=\frac{\sum_{i=1}^{n} C i(j)}{n},
$$

where $\mathrm{C} i(j)=1$ if $\mid \mathrm{M} i(j)-\mathrm{M} i$ (expert) $\mid \leq 0.5 ; \mathrm{C} i(j)=$ 0 .

The panel performances were validated only when compatible measurements were at least $80 \%$ of the total accepted measurement limit established in Perrot (2004). This algorithm was carried out using Matlab software.

Aggregation of Sensory Scores to Monitor Ripening Kinetics at the Macroscopic Level. During the interviews, the ripening process was broken down by the experts into a few key steps, closely linked to the evolution of the sensory properties of the cheese. Expert cheesemakers evaluate the proper ripening progress by using the key process steps. They pool the sensory properties of the controlled cheeses to compare it to the normal evolution. By pooling these properties, they are able to quickly recognize the situation they are overseeing and can thus anticipate possible drift. This cognitive mechanism used by experts is known as "chunk recognition," where a "chunk" is a grouped set of variables taken from a situation that are closely related to each other (Chase and Simon, 1973).

The rules used by the experts to chunk the sensory properties of the cheeses were identified. A classification rules program was then carried out using Matlab software. The program integrates sensory evaluation to establish the ripening step of a cheese as an expert might evaluate it. This classification rules program was then used during experimental trials to evaluate the ripening step of the cheeses throughout the process from the sensory indicator scores given by the assessors.

Correlation Between Sensory Kinetics and Microbiological, Physicochemical, and Biochemical Kinetics. A logistic regression was used to compare the sensory step of ripening to the microbiological, physicochemical, and biochemical data. Logistic regression is used to predict the probability of occurrence of an event by fitting data to a logistic curve. It makes use of several predictor variables that may be numerical or categorical. Logistic regression applies maximum likelihood estimation after transforming the dependent into a logit variable. Ordinal logistic regression was used because the sensory step (dependent variables) of ripening can be ranked. The success of the logistic regression can be assessed by looking at the classification table that shows correct and incorrect classifications of the dependent variable.

\section{RESULTS AND DISCUSSION}

\section{Results of Eliciting Expert Knowledge: Formalizing Sensory Indicators}

Five major sensory indicators describing the evolution of the ripening process were selected based on expert knowledge. These 5 sensory indicators were surface humidity, surface color, $P$. camemberti coat distribution, cheese reference odor, and under-rind thickness. A formal description was then drawn up with the experts: definition, operating conditions, and answer scale presented in Table 4 . The granularity of the scale was established with the experts at 0.5 , meaning that it was possible for the sensory panel to assess a sensory characteristic such as rind color with a given reference (white) or between 2 references. The aim was to cover the progression domain of each indicator during ripening. For example, rind color starts out as white and ends up being brown at the end of ripening (after 41 d). The 5 sensory indicators were then transmitted to the sensory panel, which carried out the cheese sensory assessment during the experimental design trials.

\section{Camembert Ripening Steps}

Interviews showed that expert cheesemakers distinguished 4 main chronological steps in Camembert 
ripening. The results are presented in Figure 1. In the first step, the Camembert-type cheese is characterized by high humidity on its surface, white color, and a fresh or lactic odor. In the second step, the cheese becomes less humid, the color changes progressively from white to creamy yellow, and the cheese has a white $P$. camemberti coat; and a dominant odor of mushroom is apparent. In step 3, the cheese is totally covered by the $P$. camemberti coat, the under-rind starts to grow, and the typical Camembert odor appears. Finally, in step 4 , the cheese is almost at the end of the optimal period of consumption: it has a strong ammonia odor, the under-rind thickness is complete, and the rind's color becomes darker under the P. camemberti coat. Expert knowledge is obviously not limited to these 4 steps, but it is representative of the major steps of cheese evolution during the ripening process. It helps experts to evaluate the entire ripening kinetics and detect drift from the standard evolution.

\section{Monitoring of Physicochemical, Biochemical, and Microbiological Kinetics of the Cheese Ripening Process}

Kinetics through the experimental design include the $\mathrm{pH}$ value of the cheese surface, lactose and lactate concentrations, and the microbial concentrations of K. marxianus, G. candidum, P. camemberti, and B. aurantiacum. The results obtained are presented in Figure 2 for the physicochemical variables and in Figure 3 for the microbial variables. First, it is interesting to analyze the 2 kinetics, c11 and c12, that are reached under identical temperature and RH conditions. Maximal differences for each variable, for all days, were calculated for the two experiments, c11 and c12. Just 2 values, for 19 points representing the kinetics, were above the precision of each measurement with $0.71 \mathrm{~g} / \mathrm{kg}$ for lactose, $0.38 \mathrm{~g} / \mathrm{kg}$ for lactate, 0.34 for $\mathrm{pH}$. For the other 17 values of the kinetics, the deviations were below the precision of each measurement. This means that the experiments are globally reproducible. Second, Figures 2 and 3 also show the influence of RH and temperature conditions during ripening on all kinetics: microbial, physicochemical, and biochemical. Relative humidity during ripening seemed to have an effect only on $B$. aurantiacum growth (Figure $3 \mathrm{a}$ ). Between a1 and a2 on the one hand, and b1 and b2 on the other hand, from d 20 of ripening, a difference of more than $0.5 \log _{10}(B$. aurantiacum) $\mathrm{cfu} / \mathrm{g}$ was observed. This specific effect was previously observed in Leclercq-Perlat et al. (2004) for the ripening of Camembert-type cheeses and in Bonaiti et al. (2004) for smear soft cheeses. These authors also demonstrated the small effect of $\mathrm{RH}$ on the other kinetics involved in cheese ripening.

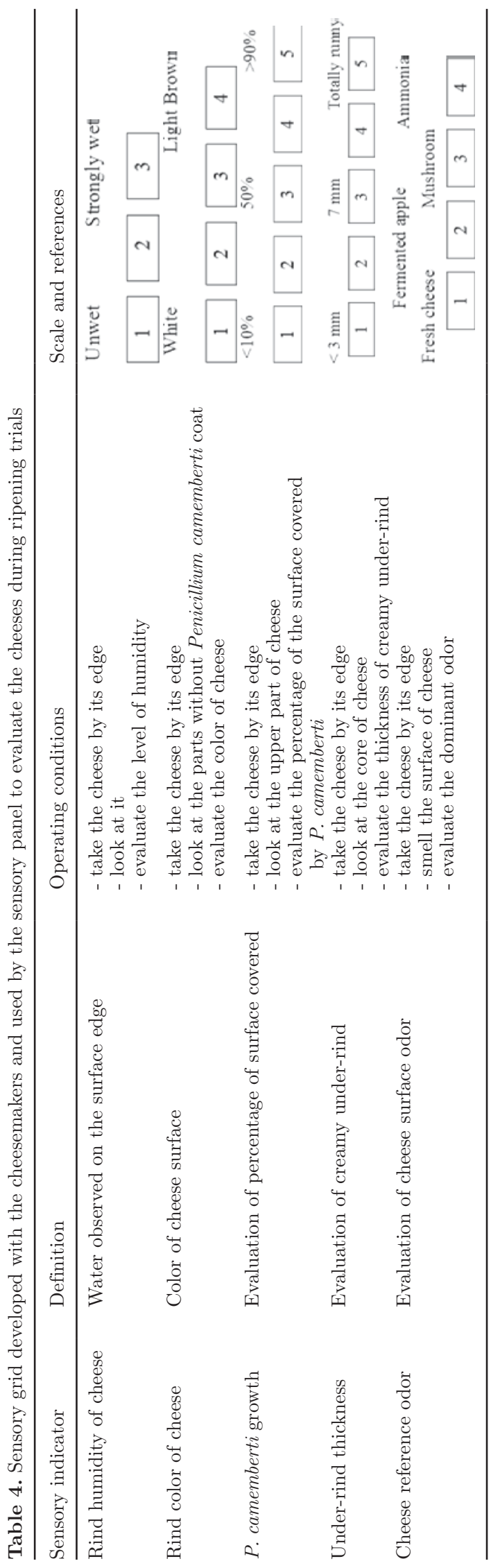




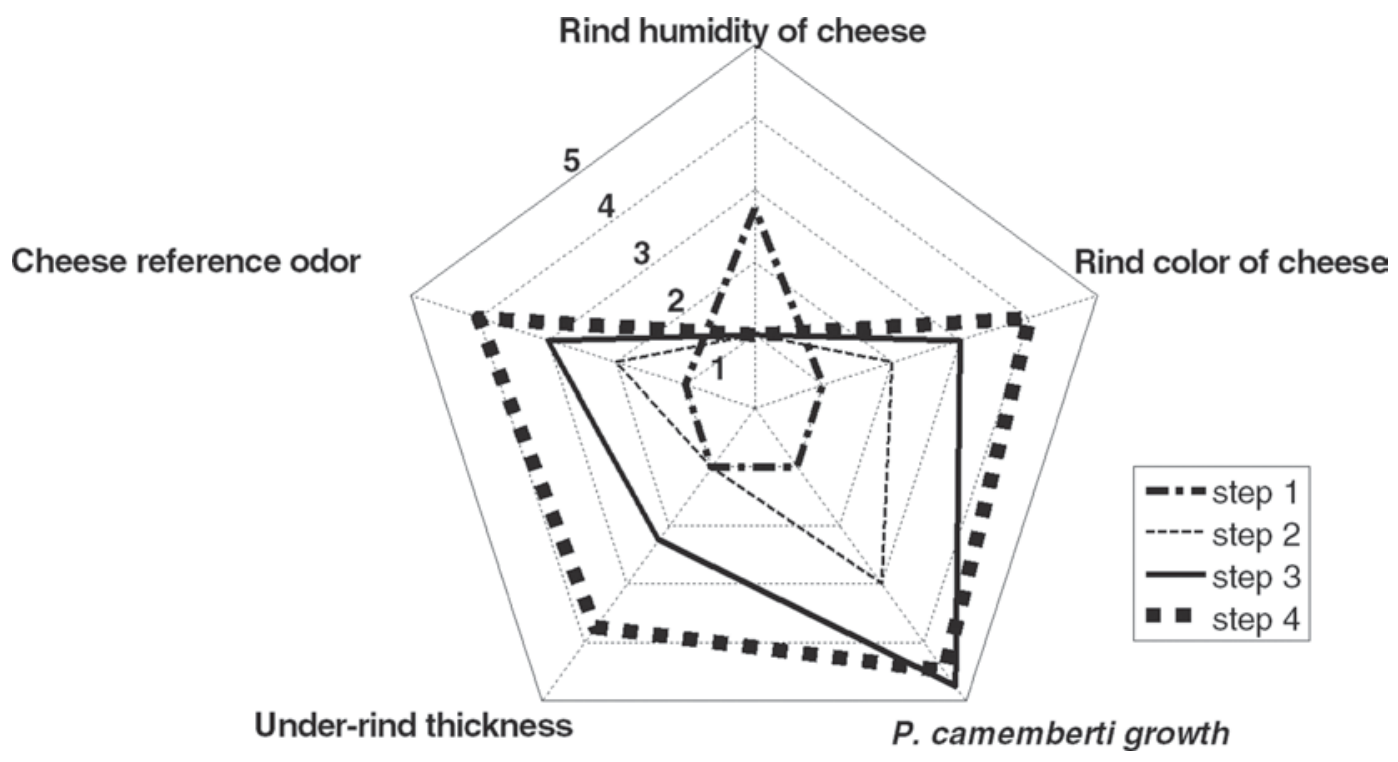

Figure 1. Evolution of cheese sensory profile throughout ripening for trials c11 and $\mathrm{c} 12\left(92 \%\right.$ relative humidity and $\left.12^{\circ} \mathrm{C}\right)$.

The initial cheese $\mathrm{pH}$ (Figure $2 \mathrm{a}$ ) was $4.7 \pm 0.05$ on average. The pH quickly increased from 4.6 to 7.5 when $P$. camemberti appeared on the cheese surface. It remained constant until the end of ripening when the $\mathrm{pH}$ was around 7.7 or 8 , depending on the experiment. The $\mathrm{pH}$, which is linked to lactate consumption, depends on the degree of activation of the microorganisms, especially $G$. candidum and $P$. camemberti. The growth of these microorganisms is known to be temperature-dependent, as reported in Leclercq-Perlat et al. (2004) and Choisy et al. (2000), with an optimal growth temperature of around $25^{\circ} \mathrm{C}$ for $K$. marxianus, G. candidum, and $P$. camemberti. The $\mathrm{pH}$ increase occurs around $3 \mathrm{~d}$ earlier under high ripening temperatures than under low ripening temperatures $\left(\mathrm{d} 5\right.$ at $16^{\circ} \mathrm{C}$ vs. $\mathrm{d} 8$ at $\left.8^{\circ} \mathrm{C}\right)$.

The number of viable cells of $K$. marxianus (Figure 3a) increases in the first days of ripening, from $10^{5}$ to around $10^{8} \mathrm{cfu} / \mathrm{g}$ of fresh cheese, and then decreases until the end of ripening. The latency before $K$. marxianus appears to be reduced when the temperature is higher. Concerning the yeast G. candidum (Figure 3b), increasing the temperature increases the rate of growth of more than the measurement precision $\left[0.5 \log _{10}(G\right.$. candidum) cfu/g] observed between d 5 and d 15 of ripening. For example, the value at d 10 of ripening is $6.74 \log _{10}$ (G. candidum) cfu/g for experiment b2, and $7.8 \log _{10}$ (G. candidum) cfu/g for experiment a2. Nevertheless, the maximal concentration reached was similar (around $10^{7.5} \mathrm{cfu} / \mathrm{g}$ ). The influence of $\mathrm{RH}$ was not significant. Interaction between $\mathrm{RH}$ and temperature was also observed. Concerning P. camemberti spores (Figure 3c), it is difficult to draw a conclusion in re- gard to precision of the measurements. The evolution of the mycelium spores in different trials, such as a1 and $\mathrm{b} 2$, seems to decrease with lower $\mathrm{RH}$ and temperature. For higher temperatures at RH of $88 \%$, the number of spores was higher but almost equal to the precision of the measurements. Growth of B. aurantiacum (Figure 3d) seemed to be influenced by both temperature and $\mathrm{RH}$. This organism grows earlier and more rapidly at high temperatures than at low temperatures. Low $\mathrm{RH}$ has a negative effect on growth of $B$. aurantiacum. The latency phase is longer and B. aurantiacum grows more slowly.

Concerning carbohydrate consumption (Figures 2b and $2 \mathrm{c}$ ), lactose and lactate were more quickly catabolized during ripening at higher temperatures. This was particularly true during the first $15 \mathrm{~d}$ of ripening with, for example, a mean difference of $7.9 \mathrm{~g} / \mathrm{kg}$ at d 10 of ripening between the experiments conducted at $16^{\circ} \mathrm{C}$ (a1, a2) and those conducted at $8^{\circ} \mathrm{C}(\mathrm{b} 1, \mathrm{~b} 2)$. Raw milk was not standardized for lactose, which accounts for the different initial concentrations of lactose and lactate between the trials.

To conclude, the results presented here are representative of previous studies carried out on the ripening dynamics of the same types of cheeses.

\section{PCA to Represent the Physicochemical, Biochemical, and Microbiological Data}

A PCA was performed on the instrumental data collected during trials a1, a2, b1, b2, c11, and c12 (Figure 4). The PCA was based on the following variables: $K$. 
marxianius, G. candidum, and B. aurantiacum growth during ripening and changes in $\mathrm{pH}$ and lactose and lactate concentrations. We chose not to include P. camemberti kinetics in the PCA because of the reduced difference between the different kinetics (see below). The first 2 eigenvectors represented 68.3 and $25.6 \%$ of the total variance, respectively. The variable projection is represented in Figure 4a. The first eigenvector represents the evolution of $\mathrm{pH}, G$. candidum growth, and lactose and lactate consumption, whereas the second axis shows the evolution of K. marxianus and B. aurantiacum. Figure 4b shows the distribution of the cheeses evaluated during the ripening process. Some cheeses are labeled according to the trial to which they belong and to the ripening day on which they were analyzed. For example, the sample a1-D5 is a cheese analyzed on d 5 of ripening during trial a1 conducted at $16^{\circ} \mathrm{C}$ and $98 \% \mathrm{RH}$. The observation a1-D5 was projected on the PCA according to the $\mathrm{pH}, K$. marxianus, G. candidum, $B$. aurantiacum, lactose, and lactate values measured on the cheese sampled.

The PCA shows the same effect of climatic ripening conditions on the microbiological, physicochemical, and biochemical kinetics as those observed in Figures 2 and 3. The effect of RH is limited until d 20 as observed, for example, for points b1-D5 and b2-D5 $\left(8^{\circ} \mathrm{C}\right)$ or a1-D20 and a2-D20 $\left(16^{\circ} \mathrm{C}\right)$, located at almost the same level of the PCA projection. The effect of $\mathrm{RH}$ on the growth of $B$. aurantiacum can be observed in the difference of the labels for the y-axis; for example, for a2-D38 and a1-D38. On the contrary, the speeding-up effect of higher temperatures is clearly visible, especially on the $\mathrm{x}$-axis, which is the synthesis of $68.31 \%$ of the information contained in the different kinetics.. Moreover, the samples are located on the map in chronological order. For example, d 5 of trials a $\left(16^{\circ} \mathrm{C}\right)$ and $\mathrm{b} 1\left(8^{\circ} \mathrm{C}\right)$ are not located in the same place. At $16^{\circ} \mathrm{C}, K$. marxianus and $G$. candidum concentrations increase more rapidly along with the $\mathrm{pH}$ than at $8^{\circ} \mathrm{C}$, whereas lactate decreases more slowly at $8^{\circ} \mathrm{C}$ than at $16^{\circ} \mathrm{C}$.

\section{Sensory Panel Training and Evaluation Results}

To follow the cheese-ripening trials as an expert would, sensory assessments were carried out during the ripening trials. Panel efficiency was checked first.

Panel performances were validated during the last training session. Experts and assessors evaluated 14 cheeses (2 for each selected day of ripening) on the same day and under the same temperature and lighting conditions. The cheeses evaluated were provided by a dairy, 2 on $\mathrm{d} 1$ of the process and 2 each on $\mathrm{d} 3,6$, $8,16,25$, and 35 . These cheeses were randomly and anonymously evaluated by the assessors monadically to

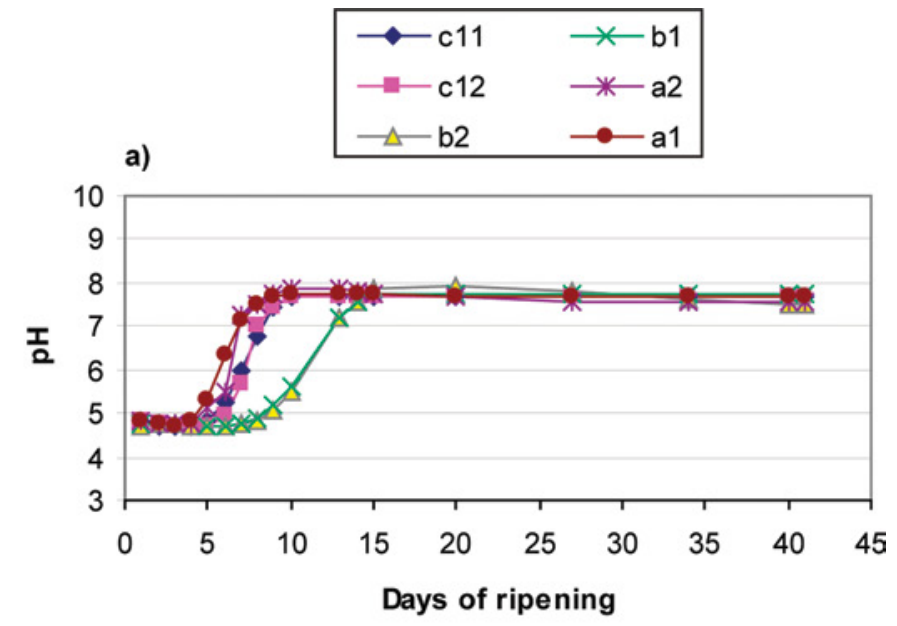

b)

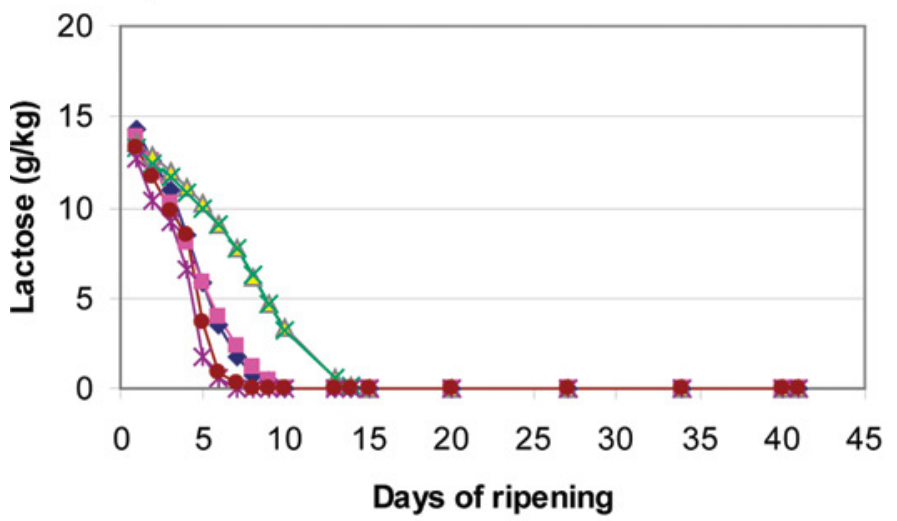

c)

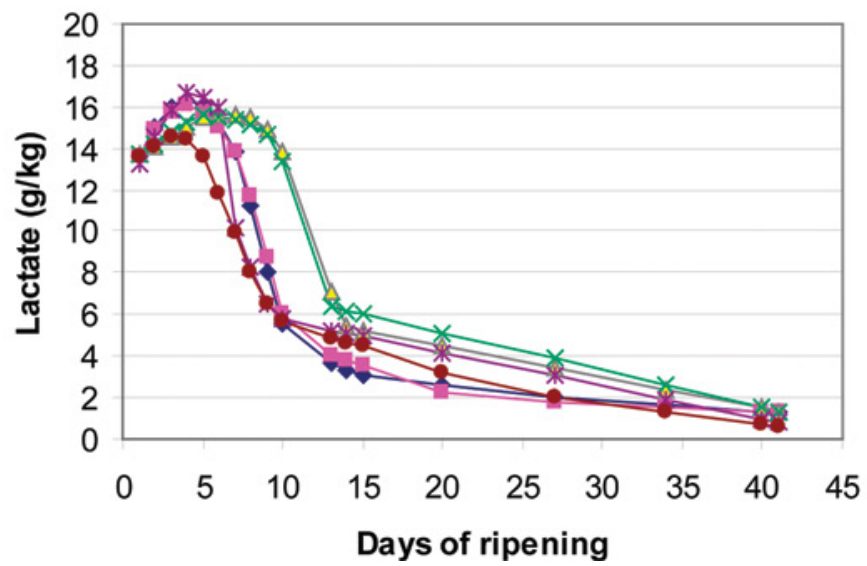

Figure 2. Influence of temperature and relative humidity on physicochemical evolutions during cheese ripening: (a) $\mathrm{pH}$, (b) lactose, and (c) lactate consumption during ripening. a1, a2, b1, b2, c11, and c12 represent different trials (different combinations of temperature and humidity as shown in Table 2). Color version available in the online PDF.

assess their discrimination capacity, their calibration, and their repeatability.

The discrimination capacity of each assessor was validated with $89 \%$ of the same results as the expert. 


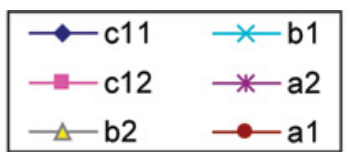

a)

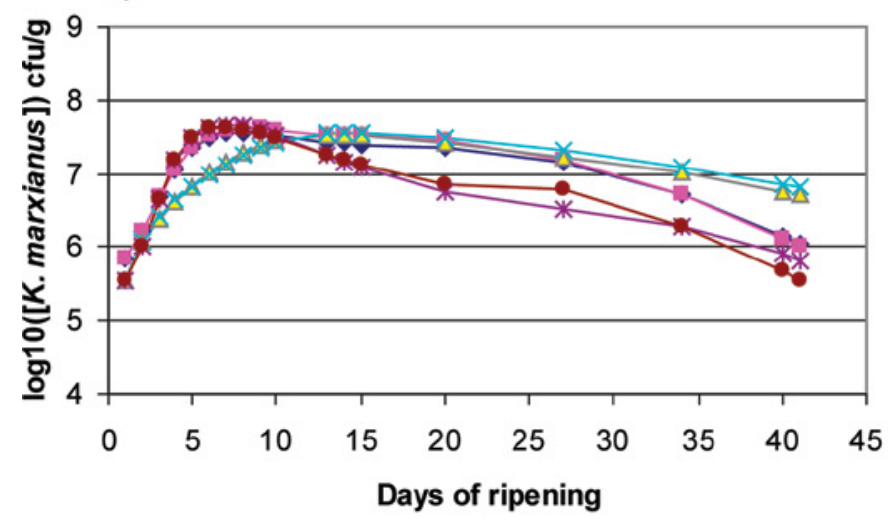

b)

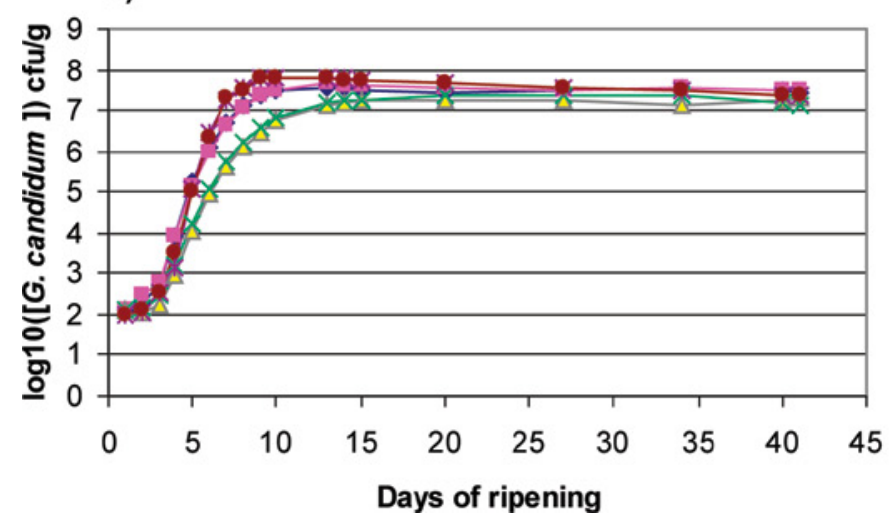

c)

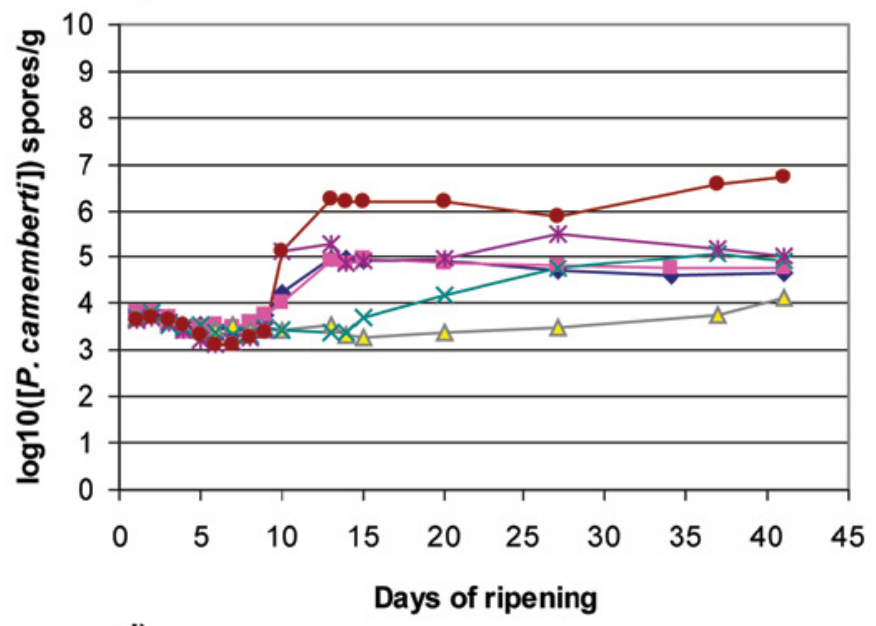

d)

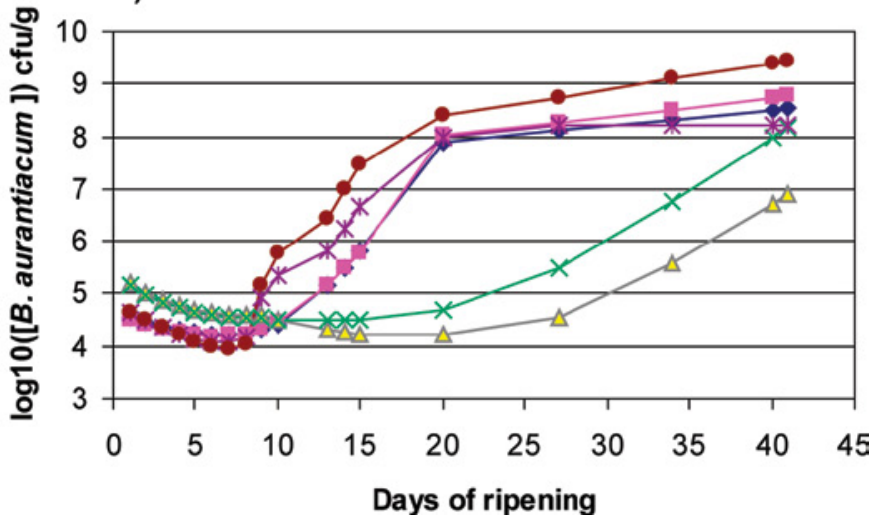

Figure 3. Influence of temperature and relative humidity on microbial evolutions during ripening: growth of (a) Kluyveromyces marxianus, (b) Geotrichum candidum, (c) Penicillium camemberti, and (d) Brevibacterium aurantiacum on the cheese surface. a1, a2, b1, b2, c11, and c12 represent different trials (different combinations of temperature and humidity as shown in Table 2). Color version available in the online PDF.

Table 5 presents the calibration and repeatability performance of the assessors. For every indicator, the level of calibration was above $80 \%$, the limit defined in earlier studies (Ioannou et al., 2002), and all the judges were repeatable within the limits of $80 \%$. Discrimination, repeatability, and calibration capacities of the sensory panel were considered satisfactory.

The sensory panel makes it possible to monitor the macroscopic evolution of cheese throughout ripening trials. The results display the ripening kinetics at varying climatic conditions based on the evolution of the 5 sensory indicators. An example of results is presented in Figure 5. This figure presents the odor kinetics for trials a1 $\left(98 \%-16^{\circ} \mathrm{C}\right)$, a2 $\left(88 \%-16^{\circ} \mathrm{C}\right)$, b1 $\left(98 \%-8^{\circ} \mathrm{C}\right)$, and b2 $\left(88 \%-8^{\circ} \mathrm{C}\right)$. Data represented are the median scores given by the assessors on the same cheese. Throughout ripening, a main cheese odor is characterized: it is described in the beginning as "lactic," evolved into "mush- room," followed by "Camembert," and terminated with "ammonia" odor. For trials a1 and a2 $\left(16^{\circ} \mathrm{C}\right)$, the figure shows that the mushroom odor appears at earlier, d 5 and $\mathrm{d} 4$, respectively, than for trials b1 and b2 $\left(8^{\circ} \mathrm{C}\right)$. However, at the end of ripening, the ammonia odor is first detected for b1, $12 \mathrm{~d}$ later for a1 and b2, and not until d 41 for a2. These results suggest that odor evolution is influenced more by temperature during the first days of ripening and more by $\mathrm{RH}$ at the end.

Concerning the other sensory indicators, the results show different evolution among the ripening temperatures and RH conditions. For the sensory indicator "humidity on cheese surface," the maximum humidity level was lower at $16^{\circ} \mathrm{C}$ than at $8^{\circ} \mathrm{C}$. The "cheese color" indicator seemed to be mostly dependent on the $\mathrm{RH}$ conditions during ripening. A "brown" color appeared earlier at $88 \% \mathrm{RH}$ than at $98 \% \mathrm{RH}$, regardless of the temperature. Likewise, the "under-rind thickness" was 
also influenced by ambient RH conditions. The underrind of cheeses at $88 \% \mathrm{RH}$ did not reach the maximal under-rind thickness until the end of ripening. For " $P$. camemberti growth," the kinetics were clearly influenced by the temperature conditions during ripening. The cheese evaluations during the 5 experiments showed that
P. camemberti grew earlier at $16^{\circ} \mathrm{C}$. The $P$. camemberti coat distribution indicator reached the maximum level around $10 \mathrm{~d}$ earlier in trial a1 $\left(16^{\circ} \mathrm{C}-98 \% \mathrm{RH}\right)$ than in b1 $\left(8^{\circ} \mathrm{C}-98 \% \mathrm{RH}\right)$. Relative humidity levels seem to have an effect on $P$. camemberti growth as well, but further trials would be necessary to confirm the result.

a)

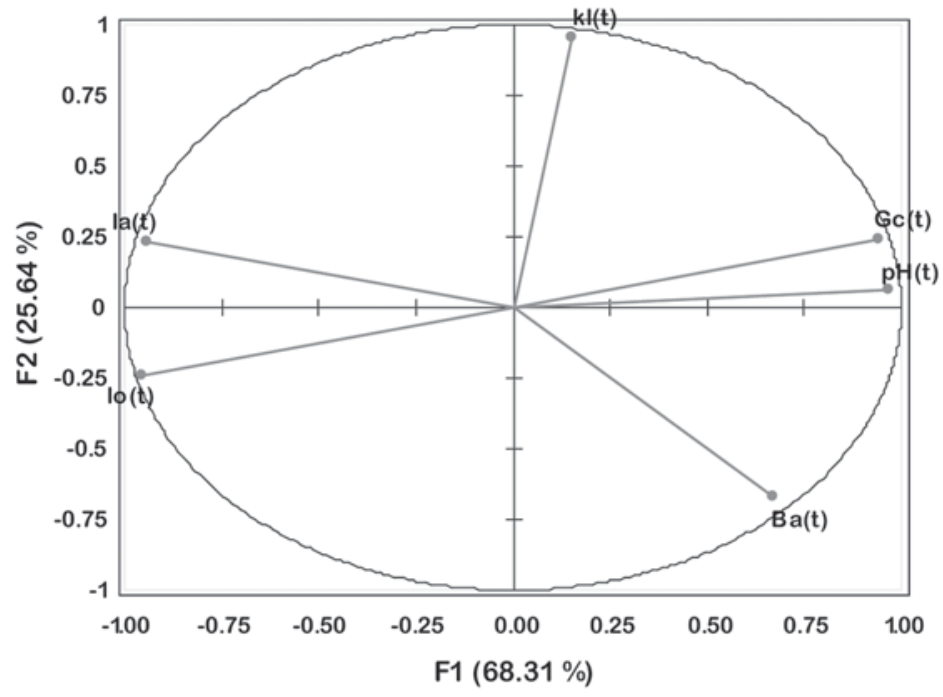

b)

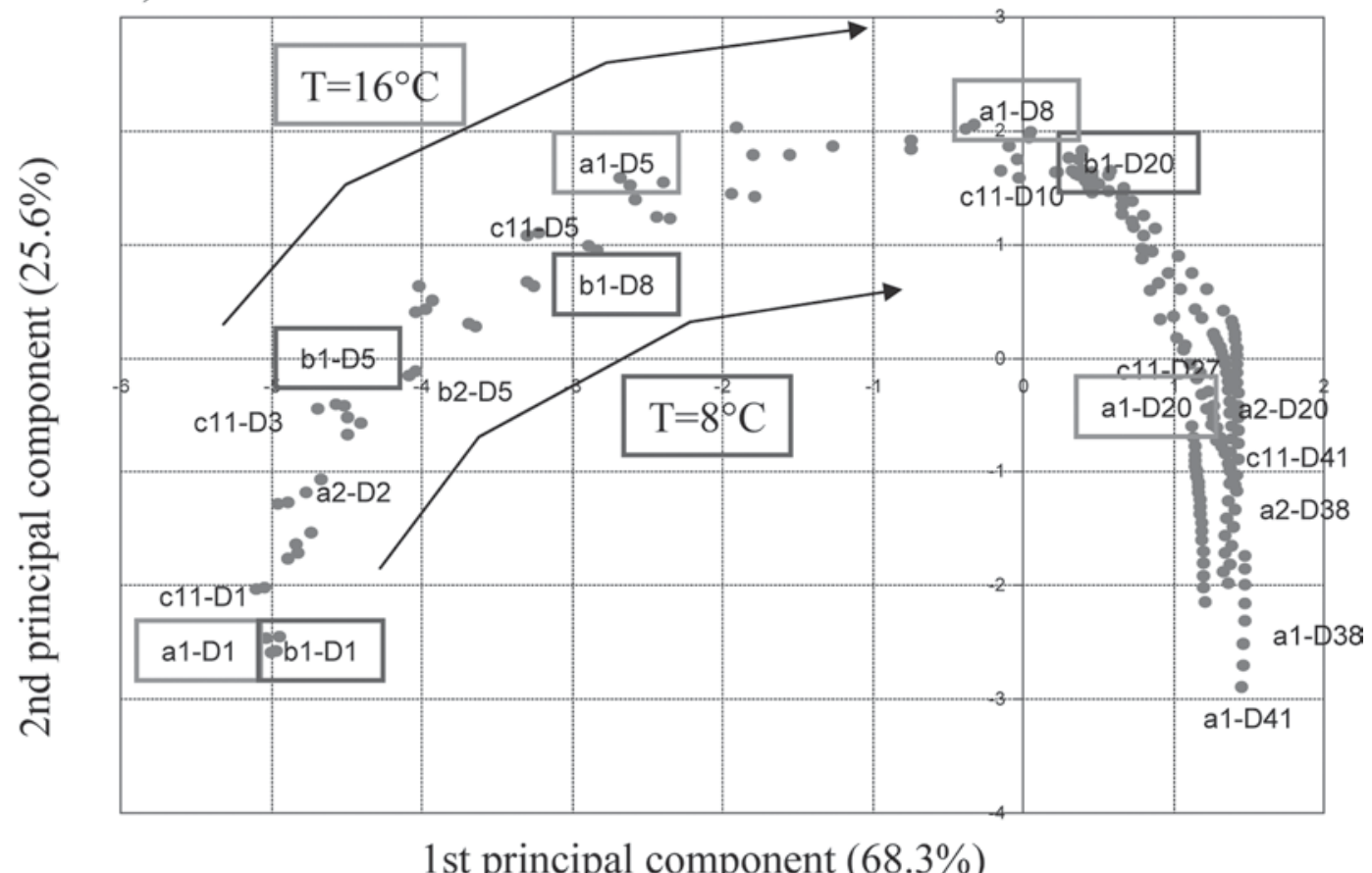

Figure 4. Influence of temperature $(\mathrm{T})$ and relative humidity on microorganism growth, carbohydrate consumption, and $\mathrm{pH}$ evolution during ripening. Principal component analysis for trials a1, a2, b1, b2, and c1 (c11 and c12): the projection on the first 2 eigenvalues (93.95\% of explained variance) is (a) the variables Kluyveromyces marxianus (kl), Geotrichum candidum (Gc), Brevibacterium aurantiacum (Ba), $\mathrm{pH}$, lactose (lo), and lactate (la); and (b) the cheese samples. D = ripening day on which chese was analyzed. 


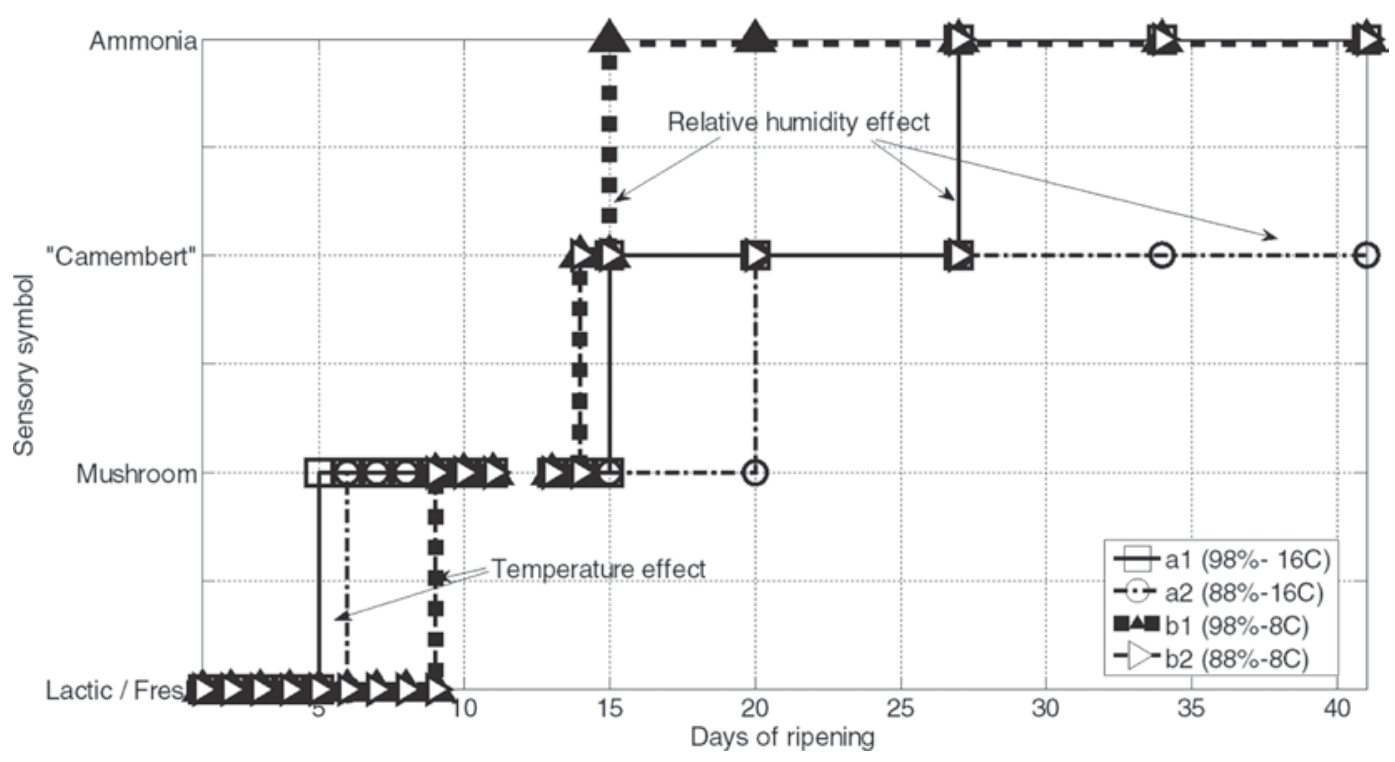

Figure 5. Evolution of cheese reference odors during ripening for trials a1 (98\% relative humidity and $\left.16^{\circ} \mathrm{C}\right)$, a2 $(88 \%$ relative humidity and $\left.16^{\circ} \mathrm{C}\right)$, b1 $\left(98 \%\right.$ relative humidity and $\left.8^{\circ} \mathrm{C}\right)$, and $\mathrm{b} 2\left(88 \%\right.$ relative humidity and $\left.8^{\circ} \mathrm{C}\right)$.

\section{Aggregation of Sensory Scores to Monitor Cheese Quality Evolution During Ripening}

During the expert interviews, the ripening evolution described by the experts was closely linked to the evolution of sensory indicators. Their knowledge was extracted to develop a classification rules program; these rules are presented in Table 6 .

For example, a cheese sample is considered to be in step 2 of the ripening process when it obtains the following scores: rind humidity $<1.5$, rind color $\geq 1.5$ (beige) and $\leq 3, P$. camemberti coat cover over at least $25 \%$ of cheese area (1.5), under-rind thickness $<3$, and main cheese odor $\geq 3$.

Finally, all the cheeses sampled during the experimental design trials were classified using their sensory scores with this classification rules algorithm.

Figure 6 is based on the same PCA that was previously presented in Figure 4. However, the cheeses are now labeled with their ripening step class calculated with the classification rules program. The cheese on $\mathrm{d} 5$ of b1 $\left(98 \% \mathrm{RH}, 8^{\circ} \mathrm{C}\right)$ is in step 1 , whereas the cheese on d 5 of a1 $\left(98 \% \mathrm{RH}, 16^{\circ} \mathrm{C}\right)$ is in step 2 of ripening. For a1, P. camemberti began to grow earlier and the sensory properties of the cheese changed. Sensory properties are linked to microbial development and the link can be observed with this step projection on the PCA. Expert steps are discriminated by the $\mathrm{x}$-axis until step 3 and by the y-axis for steps 3 and 4 . The speed-up effect observed in the PCA is also predicted by the succession of the steps over time, as described in the example below for a1 and a2 on d 5. Similarly, the combined effects of $\mathrm{RH}$ and temperature on the variables involved in the definition of the y-axis separate step 3 from step 4 on the y-axis for most points. From this second PCA, we concluded that first, the 4 steps are in chronological order and, second, the steps are not mixed, proof of the logical link between expert knowledge and recorded

Table 5. Performances (top, calibration; bottom, repeatability, \%) of the assessors on the sensory indicators

\begin{tabular}{lcccc}
\hline Indicator & Assessor 1 & Assessor 2 & Assessor 3 & Assessor 4 \\
\hline Rind humidity of cheese & 100 & 90 & 100 & 80 \\
& 100 & 100 & 100 & 100 \\
Rind color of cheese & 85 & 80 & 90 & 100 \\
& 90 & 100 & 90 & 100 \\
Penicillium camemberti growth & 85 & 80 & 85 & 100 \\
& 85 & 90 & 100 & 85 \\
Under-rind thickness & 100 & 90 & 100 & 90 \\
& 100 & 100 & 100 & 100 \\
Cheese reference odor & 90 & 85 & 90 & 85 \\
& 100 & 85 & 100 & 100 \\
\hline
\end{tabular}


Table 6. Combining expert sensory scores to link sensory perception to 1 of 4 Camembert ripening steps

\begin{tabular}{lcccc}
\hline Sensory indicator & Step 1 & Step 2 & Step 3 & Step 4 \\
\hline Cheese rind humidity & $\geq 1.5$ & $\leq 1.5$ & $\leq 1.5$ & $\leq 1.5$ \\
Cheese rind color & $\leq 2$ & $\geq 2$ and $\leq 3$ & $\geq 3$ and $\leq 4$ & $\geq 3$ \\
Penicillium camemberti growth & $<2$ & $\geq 2$ and $\leq 5$ & $>1.5$ and $\leq 4$ & $>4$ \\
Under-rind thickness & 1 & $\geq 1$ and $\leq 3$ & $\geq 3$ and $<4$ & $\geq 3$ \\
Cheese reference odor & $\leq 2$ & $\geq 2$ and $\leq 3$ & $\geq 3$ and & $\geq 4$ \\
\hline
\end{tabular}

physicochemical, biochemical, and microbiological data. The temperature effect on ripening seems to be equally observable at both the macroscopic (ripening steps) and the microscopic levels. The results obtained from the sensory panel are consistent with the microbiological, physicochemical, and biochemical results. Sensory indicators resulting from expert knowledge are therefore effective for monitoring cheese-ripening kinetics at the macroscopic level.

\section{Correlation Between Expert Sensory Property Evaluation and Instrumental Data}

A logistic regression was applied to trials a1, a2, b1, $\mathrm{b} 2, \mathrm{c} 11$, and $\mathrm{c} 12$ to compare the instrumental data $(K$. marxianus, G. candidum, B. aurantiacum, $\mathrm{pH}$, lactose, and lactate) and the ripening steps handled by the experts and calculated from the panel's sensory scores.
The model performances were cross-validated. Five out of 6 experiments were used alternatively as learning data for the regression model. This model was then applied to the data of the last trial to predict the ripening step of each cheese sample. For example, a1, a2, b1, b2, and c11 were used to build the logistic model, and c12 was the validation trial. The predicted step for each $\mathrm{c} 1$ sample was then compared with the step determined from the panel's sensory measurements performed during the trial. The results of this cross-validation are presented in a confusion matrix in Table 7. Each matrix row represents the ripening steps predicted by the model from the instrumental measurement, whereas each column represents the step determined from the sensory evaluation. One advantage of a confusion matrix is that it is easy to see if the system is confusing 2 classes. The results show a satisfactory proportion of good prediction in relation to the simple method used

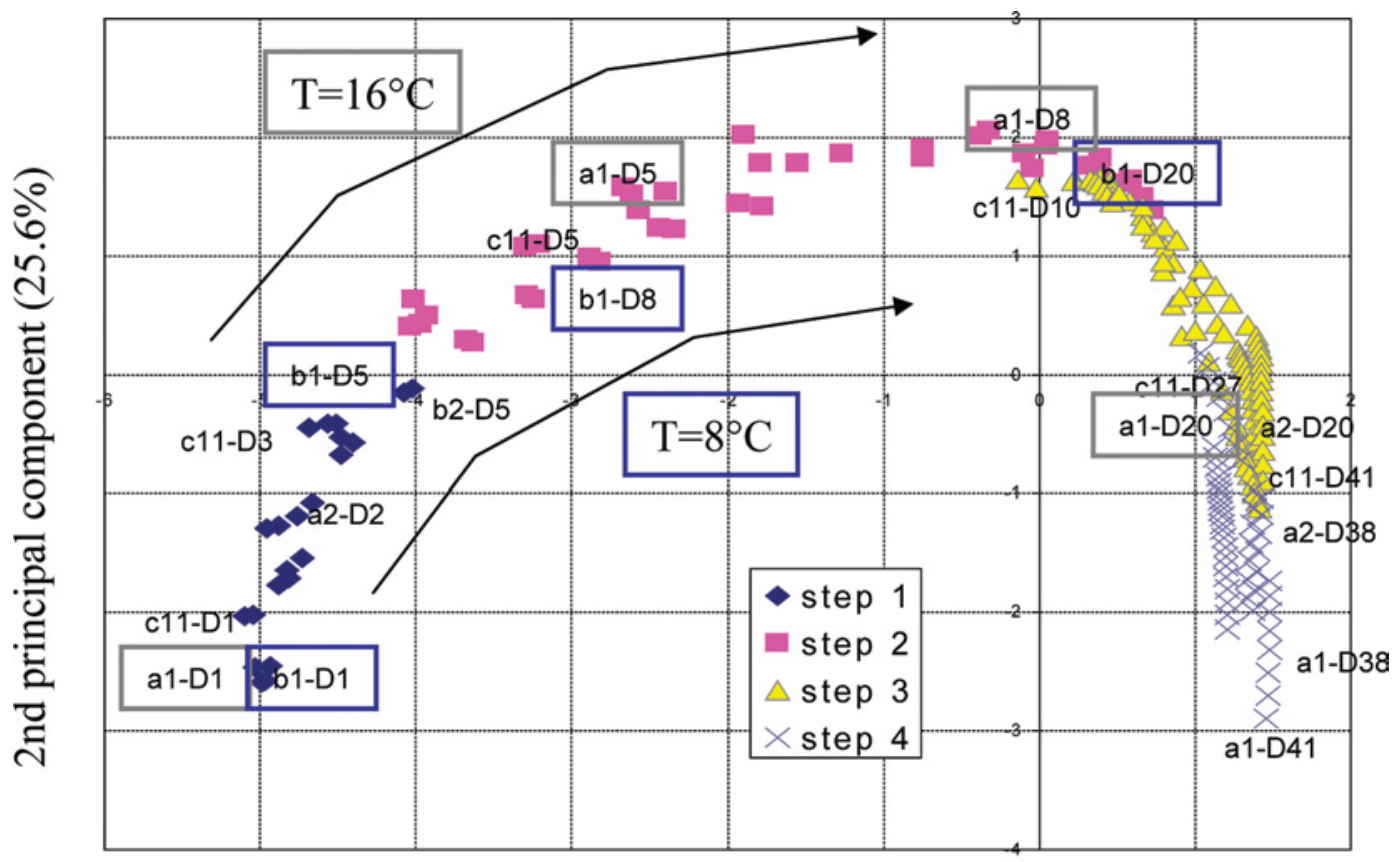

1st principal component $(68.3 \%)$

Figure 6. Influence of temperature (T) and relative humidity on cheese sensory evolution. Principal component analysis for trials a1, a2, b1, $\mathrm{b} 2$, and $\mathrm{c} 1$ (c11 and c12). The samples are projected as in Figure 3. Moreover, they were labeled with their ripening step classification, which was determined from the sensory evaluation with the classification program. D = ripening day on which cheese was analyzed. Color version available in the online PDF. 
Table 7. Confusion matrix resulting from cross-validation of the logistic model used to predict the sensory ripening steps on the basis of the measurements Kluyveromyces marxianus, Geotrichum candidum, Brevibacterium aurantiacum, $\mathrm{pH}$, lactose, and lactate concentration ${ }^{1}$

\begin{tabular}{lcccc}
\hline & \multicolumn{4}{c}{ Measured ripening step } \\
\cline { 2 - 5 } Item & Step 1 & Step 2 & Step 3 & Step 4 \\
\hline Step 1 & 33 & 4 & 0 & 0 \\
Step 2 & 2 & 19 & 7 & 0 \\
Step 3 & 0 & 3 & 8 & 3 \\
Step 4 & 0 & 1 & 4 & 18 \\
\hline
\end{tabular}

${ }^{1}$ The table represents the number of points of the cross validation classified in each step (line) in comparison to the reference steps given by the experts (column).

with a hypothesis of linear links between the steps given by the experts and the instrumental data. Seventyeight true classifications out of 102 samples $(76 \%)$ were found. The ripening steps of 24 samples were wrongly predicted. This reveals the coherence between those 2 ways of characterizing cheese ripening kinetics. This coherence is also confirmed in Baudrit et al. (2010). To summarize, based on the results revealed by this confusion matrix, we can conclude that it is possible to correlate ripening evolution at the macroscopic level from physicochemical, microbiological, and biochemical kinetics.

\section{CONCLUSIONS}

We have developed a method to formalize and integrate expert knowledge concerning a process such as cheese ripening to build decision-support systems. The coherence between expert knowledge and classical physicochemical and microbiological data are demonstrated. The use of simple logistic regression has allowed us to establish a correlation of $76 \%$ between the microbiological, physicochemical, and biochemical data, and the sensory phases measured according to expert knowledge, highlighting the efficiency of experts' measurements to manage the sensory evolution of cheese during the ripening process. In the future, this expert knowledge may be integrated into food process models to build better decision-support systems that make it possible to preserve organoleptic quality during the processes by linking them to phenomena at the microbiological, physicochemical and biochemical levels.

\section{REFERENCES}

Aldarf, M., A. Amrane, and Y. Prigent. 2002. Reconstruction of the biomass history from carbon and nitrogen substrate consumption, ammonia release and proton transfer during solid cultures of Geotrichum candidum and Penicillium camemberti. Appl. Microbiol. Biotechnol. 58:823-829.

Baudrit, C., M. Sicard, P. H. Wuillemin, and N. Perrot. 2010. Towards a global modelling of the Camembert-type cheese ripening process by coupling heterogeneous knowledge with dynamic Bayesian networks . J. Food Eng. 98:283-293.
Bonaiti, C., M. N. Leclerc-Perlat, E. Latrille, and G. Corrieu. 2004. Deacidification by Debaryomyces hansenii of smear soft cheeses ripened under controlled conditions: Relative humidity and temperature influences. J. Dairy Sci. 87:3976-3988.

Bouchon-Meunier, B., M. Rifqui, and S. Bothorel. 1996. Towards general measures of comparison of objects. Fuzzy Sets Syst. 84:143153.

Cellier, J., H. Eyrolle, and C. Marine. 1997. Expertise in dynamic environments. Results of comparison between novice and expert operators in supervision of dynamic environment. Ergonomics 40:28-50.

Chase, W., and H. A. Simon. 1973. Perception in chess. Cognit. Psychol. 4:55-81.

Choisy, C., M. Desmazeaud, J. C. Gripon, G. Lamberet, and J. Lenoir. 2000. The biochemistry of ripening. Pages $82-151$ in Cheesemaking: From Science to Quality Assurance. A. Eck and J. C. Gillis, ed. Lavoisier, Paris, France.

Curt, C., C. Francon, and G. Trystram. 2004. Optimization of the chopping process using at-line human evaluations and response surface methodology. Int. J. Food Sci. Technol. 39:1043-1052.

Farrington-Darby, T., and J. R. Wilson. 2006. The nature of expertise: A review. Appl. Ergon. 37:17-32.

Helias, A., P. S. Mirade, and G. Corrieu. 2007. Modeling of camembert-type cheese mass loss in a ripening chamber: Main biological and physical phenomena. J. Dairy Sci. 90:5324-5333.

Hoffman, R. R., N. R. Shadbolt, A. M. Burton, and G. Klein. 1995. Eliciting knowledge from experts: A methodological analysis. Organ. Behav. Hum. Decis. Process. 62:129-158.

Ioannou, I., N. Perrot, J. Hossenlopp, G. Mauris, and G. Trystram. 2002. The fuzzy set theory: A helpful tool for the estimation of sensory properties of crusting sausage appearance by a single expert. Food Qual. Prefer. 13:589-595.

Leclercq-Perlat, M. N., F. Buono, D. Lambert, E. Latrille, H. E. Spinnler, and G. Corrieu. 2004. Controlled production of Camembert-type cheeses. Part I: Microbiological and physicochemical evolutions. J. Dairy Res. 71:346-354.

Lemoine, R. 2001. L'affinage, une étape décisive pour la qualité du fromage. Revue Laitière Francaise 614:73-85.

Lenoir, J. 1983. The surface microflora and their actions during cheese ripening. Bull. IDF 171:3-19. International Dairy Federation, Brussels, Belgium.

Martin-del Campo, S. T., D. Picque, R. Cosio-Ramirez, and G. Corrieu. 2007. Evaluation of chemical parameters in soft mold-ripened cheese during ripening by mid-infrared spectroscopy. J. Dairy Sci. 90:3018-3027.

Molimard, P., L. Vassal, I. Bouvier, and H. E. Spinnler. 1995. Growth of Penicillium-camemberti and Geotrichium candidum in pure and mixed cultures on experimental mold ripened cheese of camembert-type. Lait 75:3-16.

Peres, C., F. Begnaud, and J. L. Berdague. 2002. Fast characterization of camembert cheeses by static headspace-mass spectrometry. Sens. Actuators B Chem. 87:491-497.

Perrot, N. 2004. De la maitrise des procédés alimentaires par intégration de l'expertise humaine. Le formalisme de la théorie des ensembles flous comme support. HDR. Université Blaise Pascal, Clermont-Ferrand, France.

Perrot, N., L. Agioux, I. Ioannou, G. Mauris, G. Corrieu, and G. Trystram. 2004. Decision support system design using the operator skill to control cheese ripening-application of the fuzzy symbolic approach. J. Food Eng. 64:321-333.

Picque, D., M. N. Leclercq-Perlat, and G. Corrieu. 2006. Effects of atmospheric composition on respiratory behavior, weight loss, and appearance of camembert-type cheeses during chamber ripening. J. Dairy Sci. 89:3250-3259.

Saporta, G., ed. 2006. Probabilités, analyses de données et statistique. 2nd ed. Technip, Paris, France.

Shanteau, J. 1992. Competence in experts: The role of task characteristics. Organ. Behav. Hum. Decis. Process. 53:252-266.

Trystram, G. 1996. Computerized control systems in the food industry. Pages 491-512 in Computerized Process Control for the Bakery and Cereal Industry. Marcel Dekker, New York, NY. 